\title{
Using a Local Public Good to Attract Representative Creative Class Members: The Inefficient Equilibrium Case
}

\author{
Amitrajeet A. Batabyal ${ }^{1}$, Seung Jick Yoo ${ }^{2 *}$ \\ ${ }^{1}$ Department of Economics, Rochester Institute of Technology, Rochester, New York, USA \\ ${ }^{2}$ Graduate School of International Service, Sookmyung Women’s University, Yongsan-gu, Seoul, Republic of Korea \\ Email: aabgsh@rit.edu, *sjyoo@sookmyung.ac.kr
}

How to cite this paper: Batabyal, A.A. and Yoo, S.J. (2020) Using a Local Public Good to Attract Representative Creative Class Members: The Inefficient Equilibrium Case. Theoretical Economics Letters, 10, 40-46. https://doi.org/10.4236/tel.2020.101003

Received: December 10, 2019

Accepted: January 14, 2020

Published: January 17, 2020

Copyright ( 2020 by author(s) and Scientific Research Publishing Inc. This work is licensed under the Creative Commons Attribution International License (CC BY 4.0).

http://creativecommons.org/licenses/by/4.0/

\section{(c) (i) Open Access}

\begin{abstract}
Batabyal and Beladi [1] have recently analyzed a model of competition between two cities that use a local public good (LPG) to attract members of the creative class. The creative class consists of artists and engineers and they study the behavior of a representative artist and an engineer. In this note, we explore three implications of the use of this "representative artist and engineer" modeling strategy. First, we show that the use of such a strategy can lead one to study an inefficient equilibrium in the aggregate economy. Second, we point out that in this inefficient equilibrium, the beliefs of the representative artist and the engineer are inconsistent. Finally, we contend that if we depart from the "representative artist and engineer" construct and focus instead on the entire creative class population which we model as a continuum, then the inefficient equilibrium mentioned above can be turned into an efficient equilibrium.
\end{abstract}

\section{Keywords}

Artist, Creative Class, Efficient Equilibrium, Engineer, Inefficient Equilibrium

\section{Introduction}

Richard Florida-see Florida [2] [3] [4] [5] [6], Florida, Adler, and Mellander [7]-has argued on several occasions that cities and regions that want to prosper in this era of globalization need to do all they can to attract and retain the creative capital ${ }^{1}$ possessing members of the creative class. Let us focus on cities in this note and let us also accept Florida's [2] central point that cities seeking to ${ }^{1}$ Creative capital is a more general concept than the notion of human capital. See Porter and Batabyal [8] for a more detailed discussion of this issue. 
flourish economically need to attract and retain members of the creative class. Once this is done, the obvious next question is: "How are cities to do this?" Buettner and Janeba [9], Batabyal, Kourtit, and Nijkamp [10], and Batabyal and Beladi [1] have answered this question by explaining that local public goods (LPGs) such as cultural amenities, quality schools, and public transit are a key means by which cities can usefully carry out the dual "attract" and "retain" functions. $^{2}$

Building on the prior work of Batabyal, Kourtit, and Nijkamp [10], very recently, Batabyal and Beladi [1] have studied a model of competition between two cities that use a LPG to attract members of the creative class. Using the nomenclature of Batabyal and Beladi [14], these two researchers split up the total creative class population of interest into artists and engineers. They then conduct the remainder of their analysis with a representative artist and a representative engineer.

Our objective in this note is to explore three implications of the use of this "representative artist and engineer" modeling strategy. First, we show that the use of such a strategy can lead one to concentrate on an inefficient equilibrium in the aggregate economy. Second, we point out that in this inefficient equilibrium, the beliefs of the representative artist and the engineer are inconsistent. Finally, we argue that if we depart from the "representative artist and engineer" construct and focus instead on the entire creative class population which we model as a continuum, then the inefficient equilibrium mentioned above can be turned into an efficient equilibrium.

The remainder of this note is organized as follows. Section 2.1 delineates our stylized model of an aggregate economy of two cities that is based on the prior work of Bewley [15] and Batabyal and Beladi [1]. We use this model to analyze competition between two cities when each city uses a LPG to attract and retain members of the creative class. The creative class consists of artists and engineers and we concentrate initially on the behavior of a representative artist and a representative engineer. Section 2.2 constructs an inefficient equilibrium for the aggregate economy under study. Section 2.3 shows that the beliefs of the representative artist and the engineer are inconsistent in the inefficient equilibrium of section 2.2. Section 2.4 points out that if we jettison the "representative artist and engineer" concept and concentrate instead on the entire creative class population-which we believe we can usefully model as a continuum, then the inefficient equilibrium described in Sections 2.2 and 2.3 can be converted into an efficient equilibrium. Finally, Section 3 concludes and then suggests two ways in which the research delineated in this note might be extended.

\section{The Model}

\subsection{Preliminaries}

Consider an aggregate economy that is made up of two cities denoted by the su${ }^{2}$ See Hansen and Niedomysl [11], Richardson [12], and Audretsch and Belitski [13] for a discussion of related issues. 
perscript $i=1,2$. Real world examples from the United States of the kind of cities we have in mind are 1) San Jose and San Francisco in the state of California, 2) Chapel Hill and Raleigh in the state of North Carolina, and 3) Cincinnati and Dayton in the state of Ohio. Our analysis focuses on the creative class, i.e., on the sum of the artists and the engineers, that the two cities would like to attract. Rather than model the entire creative class in a city, to illustrate our primary point, in sections 2.1 through 2.3 , we shall work with a representative artist and a representative engineer.

The representative artist and the representative engineer each have one unit of labor to supply. The preferences of these two representative members of the creative class are given by

$$
U=U\left(P^{i}\right), i=1,2,
$$

where $P^{i}$ is the amount of the LPG provided in city $i$. We make the standard assumptions that the preference functions are increasing $\left(U^{\prime}(\cdot) \geq 0\right)$ and that they are concave $\left(U^{\prime \prime}(\cdot) \leq 0\right)$. Let us denote the labor supplied by either the representative artist or the engineer in city $i$ by $L^{i}$. We now depart from Batabyal and Beladi [1] and suppose that the LPG that is provided in each of the two cities is produced with the simple, linear function given by

$$
P^{i}=L^{i} \text {. }
$$

Equation (2) tells us that the amount of the LPG provided to either the representative artist or to the representative engineer in city $i$ equals the amount of labor that is supplied by this representative member. In addition, we suppose that both cities levy a tax on labor income to finance the provision of the LPG in the city. With this description of our model out of the way, we now want to show that the use of the representative creative class member construct can lead one to focus on an inefficient equilibrium for the aggregate economy under study.

\subsection{An Inefficient Equilibrium}

To construct an inefficient equilibrium, let us begin by assuming that when choosing which city to live in, the two representative creative class members believe that the level of the LPG and the corresponding tax on labor income in each city are exogenously given. This means that these two representative creative class members do not believe that their own location choices will influence either the amount of the LPG or the tax in city $i, i=1,2$.

Suppose that one representative creative class member chooses to live in city 1 and that the other representative creative class member chooses to live in city 2 . Let the price of labor or the wage be equal to unity and let the tax levied in each city be a 100 percent income tax. In this case, each city can clearly finance the provision of one unit of the LPG. Also, given the above residential choices, this tax policy is the optimal policy because the representative artist and the representative engineer do not place any value on their labor supply (see Equation 
(1)). Note that this optimal policy is also an equilibrium because of two reasons. First, the supply of the LPG equals the demand in each city. Second, given our "exogenous beliefs" from the preceding paragraph, neither the representative artist nor the representative engineer has an incentive to migrate to the other city because a decision to migrate will have no impact on the tax policy instituted by either of the two cities.

Some thought ought to convince the reader that the equilibrium described in the previous paragraph is inefficient. To see why, observe that if both the representative artist and the representative engineer were to choose to live in the same city then this city would be able to provide two units of the LPG and such an action would clearly increase the welfare of the two representative creative class members in our aggregate economy. Our next task in this note is to demonstrate that the beliefs of the representative artist and the engineer are inconsistent in the inefficient equilibrium that we have just described.

\subsection{Inconsistent Beliefs}

Let us begin our demonstration with one representative creative class member in each city in the aggregate economy. In this case, if either representative member were to migrate to the other city then the tax revenue in the city to which this member migrated and the provision of the LPG would both double. What is happening in this instance is that our use of the representative creative class member construct is, for all practical purposes, leading to a situation in which we have two large actors in the aggregate economy. Here, we are using the term large in the sense in which this term is typically used in international trade theory. In other words, a large actor is able to influence prices-and more generally policies-with his or her own actions. ${ }^{3}$ Because the two representative creative class members are, in effect, large, their beliefs that their own actions will have no impact on the policies adopted by the two cities are inconsistent.

We now proceed to our last task in this note and that is to point out that if we discard the "representative artist and engineer" idea and concentrate instead on the entire creative class population then the inefficient equilibrium described in Sections 2.2 and 2.3 can be converted into an efficient equilibrium.

\subsection{An Efficient Equilibrium}

From an intuitive standpoint, to convert the inefficient equilibrium of Section 2.2 into an efficient one, we need to eliminate the power to influence policy possessed by the two large actors discussed in Section 2.3. One way to do this is to focus not just on the two representative creative class members but instead on the entire population of the creative class in our aggregate economy. Let us account for the point that we are now dealing with the entire creative class population by supposing that this entire population can be described by a continuum of creative class members, each of whom is a small actor relative to the aggregate economy. Here, small means that each member of the entire creative class popu-

${ }^{3}$ See Krugman, Obstfeld, and Melitz [16] for additional details on this point. 
lation is unable to control either prices or policies in either of the two cities with his or her own actions.

In this "continuum scenario," both cities levy 100 percent taxes on labor income. If they do not do this then the preference and the LPG production functions-see Equation (1) and Equation (2)-together tell us that the welfare of all the creative class members in the aggregate economy can be increased. Now, for the time being, let us focus on the case in which the creative class populations in the two cities are unequal. Then, it should be clear to the reader that the larger city will provide more of the LPG. When this happens, because the welfare of members of the creative class is increasing in the amount of the LPG that is provided, all creative class members will want to reside in the larger city.

The discussion in the preceding paragraph tells us that in the model that we are analyzing, there are two possible types of equilibria. In the first or type I equilibrium, the entire creative class population is equally divided between the two cities under study. In the second or type II equilibrium, the entire creative class population is located in a single city. In addition, the reader should note that the total number of possible equilibria is three. Specifically, there is only one possible type I equilibrium and there are two possible type II equilibria (entire creative class population resides in either city 1 or in city 2 ).

Observe that what we have called a type I equilibrium in the previous paragraph is, in fact, the equilibrium studied in Section 2.2. That said, given unequal creative class populations in the two cities, the natural incentive to migrate or the natural adjustment process in our model is such that the creative class population will always choose to live in the city in which its welfare is highest. This means that the type I equilibrium is fundamentally unstable.

In contrast to the above instability, unless our initial condition is one in which the creative class population is equally divided between the two cities, what we have called a type II equilibrium will be reached from any initial point and, moreover, this kind of equilibrium is efficient. An implication of this discussion is that the equilibrium studied in Section 2.2 does not describe an equilibrium outcome when the individual creative class members are small relative to the aggregate economy. In addition, the Section 2.2 equilibrium is not representative of what actually occurs in our model when the entire creative class population is modeled and one recognizes that in a continuum, each member is small and therefore has no influence over either prices or policies with his or her own actions. ${ }^{4}$ This concludes our discussion of the inefficient equilibrium case when cities use a LPG to attract the creative class to their city.

\section{Conclusions}

In this note, we continued a line of inquiry begun by Batabyal and Beladi [1] who studied a model of competition between two cities that used a LPG to attract members of the creative class. Specifically, we examined three conse${ }^{4}$ If we wanted to give a probabilistic flavor to this discussion then, for the reasons just given, we could say that the Section 2.2 equilibrium is, for all practical purposes, a zero probability event. 
quences of the use of a "representative artist and engineer" modeling strategy by Batabyal and Beladi [1]. First, we showed that the use of such a strategy can lead one to focus on an inefficient equilibrium in the aggregate economy. Second, we pointed out that in this inefficient equilibrium, the beliefs of the representative artist and the engineer were inconsistent. Finally, we demonstrated that if we departed from the "representative artist and engineer" construct and focused instead on the entire creative class population which we modeled as a continuum, then the inefficient equilibrium could be turned into an efficient equilibrium.

The analysis conducted in this note can be extended in a number of different directions. Here are two possible extensions. First, unlike the scenario studied in Section 2.2 , it would be useful to analyze the case where the representative artist and the representative engineer do place a value on their labor supply. Second, it would also be interesting to examine the inefficiency/efficiency of the equilibrium that we studied in this note in a setting in which cities are able to attract and retain members of the creative class with policy instruments in addition to LPGs. Studies that analyze these features of the underlying problem will provide additional insights into the inefficiency and the efficiency of equilibria in models of interactions between creative class members and cities.

\section{Conflicts of Interest}

The authors declare no conflicts of interest regarding the publication of this paper.

\section{References}

[1] Batabyal, A.A. and Beladi, H. (2019) On the Existence of an Equilibrium in Models of Local Public Good Use by Cities to Attract the Creative Class. Unpublished Manuscript, Rochester Institute of Technology, Rochester, NY.

[2] Florida, R. (2002) The Rise of the Creative Class. Basic Books, New York.

[3] Florida, R. (2003) Cities and the Creative Class. City and Community, 2, 3-19.

[4] Florida, R. (2005) The Flight of the Creative Class. Harper Business, New York.

[5] Florida, R. (2008) Who's Your City? Basic Books, New York.

[6] Florida, R. (2014) The Creative Class and Economic Development. Economic Development Quarterly, 28, 196-205.

[7] Florida, R., Adler, P. and Mellander, C. (2017) The City as Innovation Machine. Regional Studies, 51, 86-96.

[8] Porter, A. and Batabyal, A.A. (2016) Physical Capital Mobility, the Educational and Quality Aspects of Creative Capital and Output Production. Regional Science Policy and Practice, 8, 167-175.

[9] Buettner, T. and Janeba, E. (2016) City Competition for the Creative Class. Journal of Cultural Economics, 40, 413-451.

[10] Batabyal, A.A., Kourtit, K. and Nijkamp, P. (2019) Using Local Public Goods to Attract and Retain the Creative Class: A Tale of Two Cities. Regional Science Policy and Practice, 11, 571-581.

[11] Hansen, H.K. and Niedomysl, T. (2009) Migration of the Creative Class: Evidence 
from Sweden. Journal of Economic Geography, 9, 191-206.

[12] Richardson, K.E. (2009) What Lures and Retains the International Creative-Class Family? A Case Study of the Family Unit found in Vancouver's Biotechnology Sector. Comparative Technology Transfer and Society, 7, 323-345.

[13] Audretsch, D.B. and Belitski, M. (2013) The Missing Pillar: The Creativity Theory of Knowledge Spillover Entrepreneurship. Small Business Economics, 41, 819-836.

[14] Batabyal, A.A. and Beladi, H. (2018) Artists, Engineers and Aspects of Economic Growth in a Creative Region. Economic Modelling, 71, 214-219.

[15] Bewley, T.F. (1981) A Critique of Tiebout's Theory of Local Public Expenditures. Econometrica, 49, 713-740.

[16] Krugman, P.R., Obstfeld, M. and Melitz, M.J. (2015) International Economics. 10th Edition, Pearson, Boston, MA. 